\title{
FERRAMENTAS DE TOMADA DE DECISÃO PARA A ADMINISTRAÇÃO PÚBLICA SUSTENTÁVEL
}

Diego Losada Vieitez ${ }^{1}$

\begin{abstract}
Resumo: Em um contexto de sustentabilidade, compreendida como síntese harmônica de aspectos sociais, econômicos, ecológicos, político-jurídicos e éticos, a decisão pública apresenta grau elevado de dificuldade, devendo ser considerados impactos e custos direitos e indiretos. O estudo examina a necessidade de subsídios informacionais para gestão, e ferramentas nesse sentido. São abordados dois estudos de caso, o exame da política energética, e o uso de informações para melhor implantação dos Objetivos do Desenvolvimento Sustentável. O Objetivo é demonstrar os benefícios das novas ferramentas racionais de tomada de decisões, e a justificativa é a necessidade dessas para a efetivação do princípio da sustentabilidade.
\end{abstract}

Palavras-chave: Sustentabilidade; Tomada de decisão; Avaliação de impactos; Política energética; Objetivos do Desenvolvimento Sustentável

\section{DECISION-MAKING TOOLS FOR THE SUSTAINABLE PUBLIC ADMINISTRATION}

\begin{abstract}
In a context of sustainability, understood as a harmonic synthesis of social, economic, ecological, political-juridical and ethical aspects, the public decision process presents a high degree of difficulty, and must consider the direct and indirect impacts and costs. This study examines the need of information to help the decision making process and the tools in this regard. Two case are examined, the energy policy, and the use of information for the Sustainable Development Objectives. The objective is to show the benefits of the new rational decision-making tools, and the justification is the need of these for the realization of the principle of sustainability.
\end{abstract}

Keywords: Sustainability; Decision making; Impact evaluation; Energy policy; Sustainable Development Objective

\footnotetext{
${ }^{1}$ Mestrando do PPGD em Direito da Pontifícia Universidade Católica do Rio Grande do Sul (PUC-RS). Bacharel em Direito pela Universidade de São Paulo (USP). Auditor público externo do Tribunal de Contas do Estado do Rio Grande do Sul (TCE-RS).
} 


\section{INTRODUÇÃO}

A sustentabilidade é “princípio constitucional-síntese, não mera norma vaga, pois determina numa perspectiva tópica-sistemática, a universalização concreta e eficaz do respeito às condições multidimensionais da vida de qualidade” (FREITAS, 2016). Nessa linha, a sustentabilidade em sentido amplo abrange uma pluralidade de aspectos, consubstanciados nas dimensões social, econômica, ecológica, político-jurídica e ética.

Isso reflete na necessidade de as administrações públicas desenvolverem políticas públicas em múltiplos temas, desde educação até inclusão digital. Mais ainda, significa que cada política deve ser considerada conforme os efeitos indiretos, positivos ou negativos, que possa causar (como o ensino beneficiado pelo acesso à Internet), e dentro de uma perspectiva de escolher aquelas políticas que representam o melhor resultado social geral.

Para tanto, as ferramentas tradicionais de gestão, frequentemente unidimensionais, de baixa capacidade comparativa, e focadas apenas na economia de valores, restam inadequadas para a otimização do atendimento do princípio da sustentabilidade. Na presente investigação, então, serão traçadas características de ferramentas contemporâneas de administração pública, e posteriormente estudados dois casos em que podem ser aplicadas: para superar gargalos nas políticas públicas energéticas, e para melhor a efetividade dos Objetivos de Desenvolvimento Sustentável.

Com base nesse escopo, o objetivo geral deste estudo consiste então em examinar a necessidade de adotar novas ferramentas de tomada de decisões públicas racionais, considerando o reconhecimento da sustentabilidade como vetor a ser almejado pela ação governamental, as insuficiências organizacionais das administrações públicas brasileiras, a complexidade em tratar fenômenos atinentes a diversos campos, e a dificuldade em atender concomitantemente a diferentes direitos fundamentais,

A pesquisa se justifica pela necessidade da administração pública se estruturar de forma a concretizar o princípio da sustentabilidade e os direitos fundamentais decorrentes, sob pena de furtar a população do gozo desses benefícios de nova geração.

Para o desenvolvimento dos trabalhos, as diretrizes metodológicas partirão do método de abordagem hipotético-dedutivo, visando o processo de confirmação ou falseamento das hipóteses lançadas sobre os benefícios dessas ferramentas contemporâneas de gestão. Já o método de procedimento será o monográfico e as técnicas de pesquisa constituirão na consulta 
a fontes primárias e secundárias, isso é, na legislação e na produção técnica, bem como na doutrina (livros e revistas científicas) existente sobre os temas tratados.

\section{FERRAMENTAS DE TOMADA DE DECISÃO RACIONAL}

Na presente pesquisa serão abordados dois instrumentos de auxílio dos gestores na tomada de decisões: as análises custo-benefício e as avaliações de impactos. Ambas são ferramentas quantitativas de apoio gerencial, mas sem a pretensão de esgotar a matéria ou eliminar completamente outros insumos ou métodos.

Suas bases são a mensuração de aspectos econômicos, como custos monetários envolvidos, unidades de valor retornadas, e efeito nos níveis gerais de utilidade. Seus usos permitem saber se um projeto específico dará um retorno adequado, no objetivo direto e em campos circundantes, dada a quantidade de recursos envolvidos. Permitem ainda averiguar, dentre as opções de projeto disponíveis, quais darão os melhores resultados.

No campo das políticas públicas, essas técnicas podem ser usadas para examinar prestações de serviços públicos inclusive nos aspectos regulatórios, permitindo aferir se os custos de uma determinada regulamentação são proporcionais a seus benefícios, ou se a proposta ainda é válida considerando os efeitos laterais que terá em outros campos privados.

\subsection{Análise Custo-Benefício}

Essa ferramenta é a análise entre os custos envolvidos em um projeto e os retornos dado. Busca medir tanto o desempenho da opção em exame quanto suas vantagens em comparação com outras possíveis. Para tanto, identifica o quanto cada projeto aumenta o bemestar numa perspectiva, de modo que a implantação das alternativas com as melhores relações custo-benefício positivas levariam a uma melhora do ponto ótimo.

O método empregado para esse tipo de análise é o seguinte: primeiro, é identificado no que consiste exatamente o projeto e quais são os objetivos almejados, estes em quantidades monetárias tornadas líquidas por meio de métodos econométricos; depois são tratados custos e benefícios cuja aferição de valor esbarra em dificuldades como falta de valores de mercado, ou preços afetados por externalidades; em seguida, é escolhida uma técnica de análise, como por valor presente líquido ou taxa interna de retorno; e por fim, é conduzida uma análise de sensibilidade, para testar a robusteza e acrescentar informações. 
Evidentemente que essa metodologia esbarra em dificuldades de mensuração, especialmente tratando de bens públicos e custos futuros, que devem ser levadas em consideração quando se aprecia os resultados.

Ainda assim, a importância dessa ferramenta é cada vez mais reconhecida, e sua adoção ampla. Nos Estados Unidos, local cujo estudo é indispensável para entender o avanço dessa cultura de racionalização científica da atividade administrativa ndas últimas décadas, foram marcos a reorganização do Office of Management and Budget em 1970, sob a gestão Nixon, e a criação do Office of Information and Regulatory Affairs, em 1980, que ganhou poderes sob Ronald Reagan ${ }^{2}$.

No Brasil, esse movimento ganhou força com a percepção de falhas nos métodos tradicionais - e excessivamente discricionária - que vinham sendo adotados até a década de 80, resultando na adoção da chamada administração pública gerencialista, ramo brasileiro do New Public Management, cujo exame crítico vai além do escopo da presente investigação. De todo modo, nota-se que ainda há muito a se avançar, como se percebe inclusive pela forma comumente não harmônica que múltiplas esferas de regulamentação - Receitas Federal, Estadual e Municipal, órgãos ambientais também de todos os níveis federativos, Ministério do Trabalho e Emprego, Agência Nacional de Vigilância Sanitária, etc. - afetam a atividade privada. Não é por outro motivo que o Brasil é frequentemente apontado como um dos países com o maior custo de fazer negócios.

Exemplo interessante do valor desse tipo de análise sé a comparação da efetividade de diversas intervenções médicas para salvar anos de vidas (esse critério foi adotado para calcular a expectativa das vidas salvas com a intervenção, bem como o atendimento de situação que não causam morte mas diminuem a longevidade das vítimas). Segundo o levantamento apurado, que comparou os resultados de múltiplas fontes e pesquisas, vacinação para gripe para todos os cidadãos é uma despesa de US\$ 140,00 por ano de vida salva, e terapia para auxiliar pessoas entre 50-54 anos a parar de fumar custa US\$ 990,00 por ano de vida. Por outro lado, obrigar os

\footnotetext{
2 Sobre essa evolução no Direito norte-americano, se destacam as reformas profundas do pensar constitucional operadas na década de 30 sob o New Deal, pelas quais mais autonomia administrativa foi estipulado como necessário para a democracia e os direitos básicos, resultando na multiplicação das agencies. Após, esse movimento se intensificou nas décadas de 60 e 70, com a luta pelos direitos civis. Contudo, em sequência a esse apogeu, passou a ser combatido o que foi visto como uma expansão excessiva da discricionariedade dos órgãos da administração indireta, resultando, durante a Administração Reagan, na Executive Order 12291 e no State and Local Cost Estimate Act. Essas normas reforçaram um exame cuidado dos custos embutidos em atos de regulamentação e no custo das ações públicas. Apesar dessas regras e outras posteriores, como a Executive Order 12866 já durante o governo Clinton, todas no sentido de fortalecer esse exame, o resultado continua ainda não tendo a envergadura necessária (SUNSTEIN, 2003; 2015).
} 
carros a ter airbags custa US\$120.000,00 por ano de vida salvo, e proibir o uso de amianto em cilindros de acetileno custa US\$ 350.000.000,00 por ano (TENGS et al, 1995).

Reitera-se que esses valores, essa análise, são apenas subsídios para a tomada de decisão, não devendo ser adotados a qualquer custo. Contudo, não deixa de ser relevante ao administrador público observar que a simples vacinação para gripe é elemento que teria resultados muito mais positivos que outros mais chamativos.

Deve-se destacar que apesar da justificativa mais comumente apontada para a análise custo-benefício ser a eficiência ou a economia de custos (sendo esses princípios consagrados no art. 70, caput, da Constituição Federal), há outras razões tão importantes mas as vezes menos óbvias, e que serão mais adiante exploradas de forma mais aprofundada, como diminuir o poder dos grupos de interesse sob a regulamentação, e aumentar a transparência das decisões públicas ${ }^{3}$.

\subsection{Avaliação de Impacto de Políticas Públicas}

As avaliações de impactos de políticas públicas são procedimentos formais, baseados em evidências, para aferir os impactos - aqui este termo entendido de forma ampla, como abarcando aspectos econômicos, sociais, ambientais, jurídicos e de governança - das políticas.

O primeiro passo para esses procedimentos é definir o que se almeja com a política pública, o que usualmente se traduz em corrigir uma falha de mercado como falta de competitividade ou externalidades negativas. Depois são identificados indicadores representativos desse objetivo, e de outros aspectos correlatos que podem ser impactos pela implantação da política. Após, esses indicadores são acompanhados por diversos ciclos temporais. Por últimos, são empregadas técnicas econométricas de descontaminação para mensurar até que nível as mudanças observadas se devem a política, e o quanto se dá por fatores externos influenciadores.

Mundialmente, essas técnicas vêm sendo adotadas especialmente nos países-membros da OCDE e da Comissão Europeia, onde já tem grau mais acentuado de aceitabilidade. No

\footnotetext{
${ }^{3}$ Ao fim deve se observar que por mais que esse tipo de exame seja importantíssimo, sua ausência é possível desde que haja, em seu lugar, outro método para conferir e demonstrar racionalidade e proporcionalidade às decisões públicas - ou seja, outra maneira de evitar o decisionismo ou irracionalidade nas decisões. Nesse sentido, cabe destacar nos EUA a paradigmática decisão no caso Corrosion Proof Fittings, et al., Petitioners, v. the Environmental Protection Agency and William K. Reilly, a947 F.2d 1201 (5th Cir. 1991), no qual foi asseverado que "An agency may exercise its judgment without strictly relying upon quantifiable risks, costs, and benefits, but it must "cogently explain why it has exercised its discretion in a given manner" and "must offer a 'rational connection between the facts found and the choice made".
} 
Brasil, passaram a se difundir a partir do mesmo movimento de inserção de características típicas de empresas privadas na administração pública, ocorrido na década de 80, tendo encontrada grande difusão nos instrumentos de avaliação de impacto ambiental.

\subsection{Críticas e Considerações Gerais sobre essas Ferramentas}

Um relevante cuidado a ser tomado no uso dessas ferramentas é evitar que ocorra um excesso de procedimentalização. Isso porque caso se tentasse realizar exames de custobenefício ou avaliações de impacto antes de adotar qualquer ação administrativa, ou para revisar o conjunto completo de todas as medidas já em andamento, haveria custos de monta tão desmensurada que iria, em vez de auxiliar, paralisar a atividade da administração e impedir quaisquer mudanças. É como se qualquer discussão judicial levasse a debate sobre esses aspectos, inviabilizando a efetiva sindicabilidade jurisdicional da conduta pública.

Apesar desses entraves descritos, o resultado final da aplicação das ferramentas é bastante positivo, e, mais que isso, necessário para combater a irracionalidade na tomada de decisões administrativas. Questões como vieses cognitivos, falta de informação para embasamento, decisões tomadas em resposta a questões pontuais ou anedóticas, sensacionalismo da mídia e pressões de grupo de controle podem prejudicar enormemente o bem-estar social ou deturpar a ação dos gestores, e devem se adotar essas e buscar outras formas de mitigação.

Nesse sentido, o uso dessas ferramentas é hoje mais importante do que jamais foi. Isso porque é possível perceber o avanço de propostas de governo populistas em diversas regiões do mundo, causadas seja pela crescente desigualdade de renda (PIKETTY, 2014), seja pelo sentimento de repúdio e falta de representação política (discussão da qual ora nos abstemos pois ultrapassa o escopo do presente trabalho). Assim, quando se elege representantes cuja plataforma já é calcada mais intensamente em propostas sedutoras e não baseada em decisões racionais e sólidos, há um risco maior de prejuízo à gestão pública, não podendo esse populismo ser visto apenas como forma de entretenimento pelos eleitores. Aliás, não deixa de ser interessante notar que populistas estão especialmente compelidos em cumprir suas promessas de campanha, pois seus seguidores já eram volúveis desde o começo (FERGUSON, 2016).

Essa fragilidade das decisões públicas, e a necessidade do emprego de ferramentas que confiram racionalidade, é especialmente notável no campo da sustentabilidade. Isso pela 
presença acentuada tanto de grupos de interesse quanto de irracionalidade no debate, que podem ser amenizados com os instrumentos adequados.

\section{ESTUDO DE CASO: POLÍTICAS PÚBLICAS ENERGÉTICAS}

As políticas energéticas são as diretrizes gerais dadas pelo governo para a geração e distribuição desses recursos.

No Brasil, essa política é traçada pelo Conselho Nacional de Política Energética (CNPE), que propõe ao Presidente da República medidas para o setor; pelo Ministério das Minas e Energia (MME), que acompanha os programas da área e implementa políticas; a Empresa de Pesquisa Energética (EPE), que realiza pesquisas e estudos para o planejamento do Setor; e agências reguladoras como a Agência Nacional de Energia Elétrica (ANEEL), a Agência Nacional de Petróleo, Gás Natural e Biocombustíveis (ANP), e outros. Ainda são importantes agentes do mercado a Petrobrás, empresa com atividade mundial e líder do setor de hidrocarbonetos no Brasil, e a Eletrobrás, empresa com forte atuação no mercado interno de produção e distribuição de energia elétrica.

Os mercados energéticos no Brasil, tanto de petróleo quanto de eletricidade, foram marcados por mudanças de paradigma na década de 90, quando foi superado o monopólio público (conceitualização anterior da produção energética como questão de base estratégica para segurança nacional) com substancial abertura para participação privada (novo conceito de energia como commodity com produção ótima a ser alcançada pelos mecanismos de mercado). Esses processos tiveram início no governo de Fernando Collor, mas tiveram continuidade nos governos subsequentes de Itamar Franco, Fernando Henrique Cardoso, Luís Inácio Lula da Silva, Dilma Roussef e Michel Temer.

Feitas essas considerações, passa-se a examinar o cenário local e mundial. Para tanto, observa-se que a comparação entre a matriz energética brasileira e a mundial, referente ao ano de 2013, revela que apesar de a situação brasileira ser um pouco melhor - Brasil possui um dos parques de geração elétrica mais limpos do mundo, com 41,1\% de suas fontes vindas de energia elétrica, com destaque para a hidrelétrica e os derivados de cana como álcool e biomassa, ao passo que a matriz limpa mundial é de 13,5\% -, ainda há muito a melhorar. Observa-se que o consumo brasileiro de petróleo é, relativamente, maior que a média mundial (39,2\% a 31,2\%), resultado de seu perfil de economia emergente com transporte baseado em rodovias. O ponto 
em que o Brasil claramente apresenta vantagem é no uso de carvão (5,6\% nacionalmente contra a média mundial de 29,3\%) (VENTURA FILHO, 2015).

Afortunadamente, há condições para tais melhoras: o Brasil tem o terceiro maior potencial hidrelétrico no mundo, atrás apenas da China e da Rússia, e possui potencial para energia solar e eólica entre os três maiores também. Isso além da já citada produção de bagaço de cana, características brasileiras.

Esses métodos de produção energética renovável possuem vantagens que poderiam ser aproveitadas, como grande disponibilidade em território nacional; competitividade econômica; tecnologia nacional já desenvolvida; e viabilidade ambiental.

Diante desse cenário, cabe investigar como está sendo realizado tal aproveitamento. O primeiro ponto de destaque é o Plano Nacional de Energia 2030, elaborado em 2007 pelo Ministério de Minas e Energias como primeiro grande estudo de planejamento de recursos energéticos integrados. Tal Plano previa o incremento relativo do uso do carvão, a manutenção relativa da exploração do potencial hidrelétrica, e, no âmbito das energias renováveis, o incremento da energia solar e da energia eólica.

O segundo ponto a ser sublinhado, mais recente, foi o resultado de procedimento fiscalizatório realizado pelo Tribunal de Contas da União para avaliar a gestão da política energética, no qual foi relatada a falta de estudos identificando claramente os “custos $e$ benefícios econômicos e socioambientais da utilização de cada tecnologia de geração de energia elétrica (hidrelétrica, termonuclear, térmica convencional, etc.) considerando as possibilidades, os requisitos e os efeitos de sua inserção na matriz energética brasileira e na expansão do parque gerador, com base em critérios que propiciem o compromisso adequado entre segurança energética, economicidade, aí incluídas as imperiosas qualidades relacionadas à modicidade tarifária e ao cumprimento dos acordos internacionais e legislação ambientais, especialmente aos relacionados à contenção/redução da emissão de gases produtores do efeito estufa" (Processo n. 012.949/2013-2, Rel. Min. Sherman Cavacanti, sessão de 07-05-2014). Como se percebe, identificou-se que a gestão energética vem sendo realizada sem se atentar para a sustentabilidade ambiental, em desobediência ao comando contigo no art. 225 da Constituição Federal.

Como se percebe por esses pontos destacados, independente da premência da questão ambiental, tanto pela contundente ameaça existencial quanto até pelos compromissos internacionais firmados pelo Brasil, a questão da sustentabilidade ambiental na política 
energética não está obtendo a atenção necessária ${ }^{4}$, nem as decisões estão sendo tomadas de forma racional e científica.

\subsection{Aplicação das Ferramentas de Tomada de Decisão Racional na Política Energética}

Como exposto, há diversas vantagens na adoção de uma política energética sustentável. Ainda assim, caminha-se longe disso.

Apesar de poderem ser apontados uma série de possíveis motivos para isso, nenhum se destaca tanto quanto a questão política. Isso porque em países com grandes produções domésticas de hidrocarbonetos, esses agentes econômicos acabam acumulando poder considerável para exercer na arena da tomada de decisões públicas. A indústria do carvão, petróleo e gás acaba sendo, frequentemente, um dos mais poderosos grupos de lobby em todos os países em que está presente. Como muitos desses são ainda países de enorme influência geopolítica, como Estados Unidos, China e Rússia, isso se reflete numa incapacidade de comprometimento com mudanças maiores.

Mundialmente, isso se reflete na enorme dificuldade, mesmo desde a Conferência das Nações Unidas sobre Meio Ambiente e Desenvolvimento de 1992, em obter consenso num mecanismo internacional para impedir a escalada da emissão de gases do efeito estufa. O Protocolo de Kyoto de 1997 fracassou em obter resultados significativos, mesmo porque os Estados Unidos nunca o ratificaram, a Austrália e Canadá nunca cumpriram, e seus dispositivos não vinculavam a China. Quanto ao Acordo de Paris de 2015, ainda é cedo para saber seus resultados, mas já se encontra periclitante pela saída dos Estados Unidos do tratado.

Em nível nacional, uma série de pontos convergem para dificultar a mudança da matriz, havendo interesses econômicos profundos de setores de base, energia e transporte, nos campos públicos e privados. Isso além de uma resistência em assumir para si a responsabilidade por parte da mudança, quando grande parte dos danos foram historicamente causados, em considerável proporção, pelos países hoje desenvolvidos.

\footnotetext{
${ }^{4}$ Note-se que isso não significa que não haja preocupações nos gestores energéticos com a questão ambiental, o que se externaliza em diversos pronunciamentos e compromissos, e também na elaboração de programas de sustentabilidade de qualidade reconhecida. Para exemplificar um nesse sentido, cita-se o PROINFA (Programa de Incentivos a Fontes Alternativas de Energia), criado pela Lei Federal n. 10.438/02, que teve papel-chave na expansão da energia eólica no país.
} 
Apesar dessas razões não serem suficientes para justificar a inação diante de uma ameaça do porte da mudança climática, ainda assim produzem um vasto efeito.

As ferramentas contemporâneas já descritas são importantes para evitar esse efeito. A análise de custo-benefício e a avaliação de impactos diminuem a margem para decisões desvinculadas do interesse público, pois deixam evidentes quais propostas são benéficas e quais não.

Demandando uma fundamentação adequada dos atos públicos, e vinculando e exigindo tal demonstração de forma inequívoca dos administradores, pode-se chegar a um nível de sindicabilidade contra o qual interesses indevidos ou mesmo vieses não conseguiram se impor. Isso além do fortalecimento da transparência que a exposição clara dos motivos científicos para tomada de decisões permite, dando meios e incentivos para a sociedade civil se organizar e barra excessos.

Para tanto, as análises de benefícios das políticas públicas energéticas devem ser realizadas considerando não somente o papel do ambiente enquanto insumo produtivo, mas também enquanto ecossistema mantenedor da existência da civilização humana. A mensuração do papel do ambiente nesse sentido, apesar de difícil, é indispensável.

Assim, o valor econômico total do ambiente pode ser dividido da seguinte forma: o valor do uso direto (do produto de que um sistema fornece para uso comercial ou nãocomercial); o valor do uso indireto (o papel do ambiente na manutenção do clima); o valor opcional (o quanto as pessoas pagariam para garantir a continuidade futura de um recurso ambiental que estivesse ameaçado); e o valor existencial (aquele conferido a um ambiente independente de seu uso, apenas pela felicidade que gera por ser).

\section{ESTUDO DE CASO: OS OBJETIVOS DO DESENVOLVIMENTO}

\section{SUSTENTÁVEL}

Os Objetivos do Desenvolvimento Sustentável (ODS) são os sucessores dos Objetivos de Desenvolvimento do Milênio (ODM), grupo de metas focadas na erradicação da pobreza e alguns temas correlatos que foram almejados pelos Estados-membros da ONU de 2000 até 2015.

A partir do sucesso desses ODM foram elaborados os ODS, novo conjunto de objetivos intergovernamentais, agora numa perspectiva ampla multidimensional de sustentabilidade, a serem perseguidos pelos Estados-membros até 2030.

Revista de Direito Ambiental E Socioambientalismo | e-ISSN: 2525-9628 | Salvador | v. 4 | n. 1 | p. 78 - 95 | Jan/Jun. 2018 


\subsection{Objetivos de Desenvolvimento do Milênio}

Vale traçar considerações preliminares sobre os ODM, por terem sido a origem dos ODS. Nesse sentido, os ODM foram oito objetivos adotados pela Assembleia Geral da Organização das Nações Unidas, na Declaração do Milênio em 8 de setembro de 2000. Mais especificamente, os objetivos eram (1) acabar com a fome e a miséria; (2) educação básica de qualidade para todos; (3) igualdade entre sexos e valorização da mulher; (4) reduzir a mortalidade infantil; (5) melhorar a saúde das gestantes; (6) combater a AIDS, a malária e outras doenças; (7) qualidade de vida e respeito ao meio ambiente; (8) todo mundo trabalhando pelo desenvolvimento.

Desde a concepção dos ODM, verifica-se que, de fato, houve ganhos significativos nas dimensões almejadas:

- a taxa de pobreza extrema nos países em desenvolvimento caiu de $47 \%$ para $14 \%$, de 1990 a 2015 (objetivo 1);

- a taxa de matrícula na educação infantil nos países em desenvolvimento aumentou de 83\% para 91\%, entre 2000 e 2015 (objetivo 2);

- a quantidade de meninas matriculadas no ensino primário no Sudeste Asiático cresceu de 74 garotas para cada 100 garotos em 1990, para 103 garotas para cada 100 garotos em 2015 (objetivo 3);

- a mortalidade infantil caiu de 90 casos em cada 1.000 nascimento para 43 em cada 1.000, de 1990 a 2015 (objetivo 4);

- a penetração mundial da internet aumentou de 6\% para $45 \%$ da população, de 2000 a 2014 (objetivo 8).

Não se pode deixar de registrar que o alcance dos objetivos não se deu uniformemente entre os países, com o Brasil tendo sucesso na maior parte deles (Konrad Adenauer Foundation, 2012). Outra história de sucesso é a da China em relação à erradicação da pobreza extrema, com a queda da taxa de 61\% da população em 1990 para 4\% em 2015.

Apesar desse cenário ter diversos aspectos favoráveis e poder gerar maior otimismo, não se pode deixar de registrar que nem todos os ODMs foram cumpridos, como o de melhorar a saúde das gestantes (objetivo 5), no qual a métrica buscada era de reduzir em 75\% a 
quantidade de mortes maternas associadas ao parto em 2015 em comparação com a quantidade de 1990, mas só se obteve redução de 45\%. Também se nota, retomando a observação anterior de que o cumprimento dos objetivos não se deu de forma uniforme entre os países, uma taxa de fracasso muito maior na África subsaariana. Ainda, não se pode ignorar que nem todos os avanços registrados foram causados pelos ODM, sendo consenso que a redução fenomenal da miséria na China se deu pelo crescimento econômico daquele país.

De todo modo, essas objeções não anulam o efeito positivo que os ODM tiveram até 2015, quando serviram de ponto de foco para os tomadores de decisão e como catalizadores na arrecadação de recursos.

Contudo, um ponto especial de crítica se sobressai: os ODM eram limitados em sua ambição e focavam na pobreza, não considerando plenamente todas as múltiplas instâncias interconectadas que marcam a sociedade em suas dimensões social, ética, ambiental, econômica e jurídico-política. Questões de maior complexidade e de escala global, como as crises econômicas, o aumento do preço de alimentos e o contínuo desrespeito aos direitos humanos, estão foro do escopo dos ODM.

\subsection{Objetivos de Desenvolvimento Sustentável}

Apesar dos avanços verificados no período dos ODM, permanecem a desigualdade de gênero, a enorme disparidade econômica entre os mais pobres e os mais ricos, a degradação ambiental que afeta especialmente os mais pobres, os conflitos violentos, e a situação de miséria de centenas de milhões de pessoas.

Diante desse cenário, e com o fim do prazo dos ODM em 2015, os Objetivos de Desenvolvimento Sustentável foram adotados como seus sucessores pela Assembleia Geral da ONU, com prazo final para as metas em 2030.

Os ODS são compostos dos seguintes objetivos: (1) erradicação da pobreza; (2) fome zero; (3) boa saúde e bem estar; (4) educação de qualidade; (5) igualdade de gênero; (6) água limpa e saneamento; (7) energia acessível e limpa; (8) emprego digno e crescimento econômico; (9) indústria, inovação e infraestrutura; (10) redução das desigualdades; (11) cidades e comunidades sustentáveis; (12) consumo e produção responsáveis; (13) combate às alterações climáticas; (14) vida debaixo d’água; (15) vida sobre a terra; (16) paz, justiça, e instituições fortes; e (17) parcerias em prol das metas. 
Como se observa, os ODS, além de repetir objetivos de seu antecessor como erradicação de pobreza e educação de qualidade, têm um escopo mais ambicioso de 17 dimensões com 169 metas, incorporando especificamente e explicitamente questões como energia limpa, emprego digno e crescimento econômico, e infraestrutura sustentável.

A ideia subjacente é de que não basta a simples redução da pobreza por programas como de transferência direta de recursos, pois dada a multidimensionalidade dos fatores componentes do ambiente humano é necessário que todos sejam considerados para alcançar o bem-estar social sustentável e perene ${ }^{5}$. Ban-ki Moon se expressou sobre isso no seguinte sentido:

Este é o programa para o povo, um plano de ação para acabar com a pobreza em todas as suas dimensões, irreversivelmente, em todos os lugares, e sem deixar ninguém para trás. Ele busca garantir a paz e a prosperidade, e forjar parcerias com as pessoas e o planeta no núcleo. Os 17 Objetivos de Desenvolvimento Sustentável, integrados, interligados e indivisíveis são os objetivos das pessoas e demonstram a escala, universalidade e ambição desta nova agenda (NAÇÕES UNIDAS, 2015).

Em tom semelhante de otimismo, o professor Jeffrey Sachs argumentou que os ODS são um importante passo rumo à sustentabilidade, pois a definição de objetivos causa mobilização social, pressão por resultados, e a construção de comunidades de especialistas (2015). De todo modo, o sucesso dos ODS vai depender das medidas operacionais de implementação concretas adotadas ${ }^{6}$.

\subsection{Os Indicadores dos Objetivos de Desenvolvimento Sustentável e a Importância de Informações para Tomada de Decisões}

Um instrumento indispensável para as tomadas de decisões que levem ao desenvolvimento sustentável é o uso de informações robustas e confiáveis no planejamento, execução e controle das políticas públicas.

\footnotetext{
${ }^{5} \mathrm{Um}$ aspecto interessante que revela a diferença entre os ODM e os ODS foi o processo de desenvolvimento: enquanto os ODM foram elaborados por um grupo pequeno operando casualmente em um escritório da ONU (MALLOCH-BROWN, 2012), os ODS foram o resultado de anos de trabalhos de um grupo de trabalho intergovernamental com representantes de setenta países, além de consultas temáticas e nacionais. Assim, podese dizer que os objetivos são complexos pois reconhecem a complexidade dos problemas envolvidos.

${ }^{6}$ Um aspecto vital da implementação dos ODS, que não será ora tratado a fundo por fugir do escopo deste trabalho, é o financiamento. Um relatório da Conferência das Nações Unidas para o Comércio e o Desenvolvimento diz que há um déficit de financiamento anual de US\$ 2,5 trilhões para os ODS. Buscando superar esse problema uma conferência foi realizada em Adis Abeba em julho de 2015, na qual foram discutidas reformas tributárias e o combate aos fluxos financeiros ilícitos, medidas inseridas na perspectiva multidimensional das ODS. Contudo, não foram criados novos mecanismos de investimento direto nos objetivos.
} 
As informações permitem que a tomada de decisões seja feita com base em evidências que indiquem quais políticas estão produzindo bons resultados e quais não, ou em que campo temático ou localidade geográfica é necessário empregar mais recursos. Isso é possível por possibilitarem as análises de custo-benefício e as avaliações de impacto. Assim, aumentam a eficiência dos procedimentos e a efetividade dos resultados, minimizando ainda impactos indesejáveis.

Desse modo, o uso de dados quantitativos faz com que os objetivos de desenvolvimento se tornem ferramentas gerenciais uteis na escolha de estratégias e alocação de recursos, assim como no acompanhamento de resultados e correção de cursos. Nessa linha:

\footnotetext{
Ao contrário de tantas resoluções internacionais escritas de forma vaga, os ODM vieram com números concretos. Você pode usar os objetivos para mensurar o progresso pelo mundo e em países específicos (...). E as medidas se aplicam a coisas sob as quais todos podem se unir, como salvar a vida de crianças e prevenir a mortalidade maternal. Eu venho escrevendo sobre mensuração muito este ano, porque descobri que medir o progresso é a única maneira de conseguir sucesso duradouro (GATES, 2013).
}

Contudo, quando os ODS foram inicialmente apresentados, não foram acompanhados por indicadores, metas quantificadas, que permitissem essa mensuração dos progressos para cada um dos 17 objetivos e 169 metas.

Para suprir essa necessidade, após trabalhos iniciais da Rede de Soluções para o Desenvolvimento Sustentável das Nações Unidas (UN Sustainable Development Solutions Network - SDSN), foi criado em março de 2015 o Grupo Inter-agência Especialista nos Indicadores dos ODS (Inter-agency and Expert Group on SDG Indicators - IAEG-SDGs), composto principalmente de representantes dos órgãos de estatística nacional de paísesmembro (como o IBGE brasileiro).

O IAEG-SDG, em março de 2016 após um ano de estudos, acordou internamente em 230 indicadores para os ODS. Esse conjunto foi aprovado na $48^{\mathrm{a}}$ sessão da Comissão de Estatística das Nações Unidas, reunidas em março de 2017.

Tais indicadores têm como base as informações produzidas pelos sistemas nacionais de estatística (que poderão ser complementados pelas informações produzidas em nível regional ou mundial). Deve-se notar que esta lista não é final, e poderá ser aprimorada conforme necessário durante o período de vigência dos ODS. 
Certamente para o sucesso dos ODS será necessário a adoção de métodos céleres e confiáveis de coleta de dados. Esclarecendo tal fato, o Subsecretário-Geral para Assuntos Econômicos e Sociais das Nações Unidas, Wu Hongbo, fez constatação no sentido de que “Os indicadores dos ODS requererão a produção e análise de uma quantidade inédita de dados e é evidente que isto representará um desafio significativo para os sistemas de estatística nacional, tanto em países em desenvolvimento quanto em países desenvolvidos”.

\subsection{Custo-benefício na Persecução de cada ODS}

Outra maneira que as informações gerenciais podem ser úteis é em priorizar a alocação de recursos entre os diferentes objetivos e metas - sem deixar qualquer um deles de fora, o que contrariaria a própria ideia de sustentabilidade.

Conforme críticas do Copenhagen Consensus, um think tank que busca estabelecer prioridades em objetivos globais usando análise custo-benefício, as 169 metas do ODS são muita variadas tanto no grau de possibilidade de serem alcançadas, quanto na quantidade de benefício que geram.

De acordo com Bjørn Lomborg, o presidente do instituto, uma pesquisa conduzida por um grupo de eminentes economistas, incluindo dois ganhadores do Nobel, apontou que 19 das metas geram resultados extremamente significativos e devem ser colocadas na frente das demais.

Por exemplo, a tuberculose é uma doença que chama pouca atenção, mas ainda mata um grande número de vítimas e seu tratamento é barato - cada 1 dólar gasto no diagnóstico e tratamento da tuberculose representa um retorno de 43 dólares em vida produtiva. Semelhantemente, investindo na nutrição infantil as crianças se desenvolvem melhor e se tornam membros produtivas da sociedade, de modo que cada 1 dólar gasto nesse campo gera 45 dólares de benefício social a longo prazo.

Também se destaca cortar os subsídios aos combustíveis fósseis, o que geraria US 550 bilhões de dólares mundiais para serem investidos em fins públicos, além de reduzir as emissões de $\mathrm{CO} 2$.

Outros objetivos que gerariam benefícios superiores são diminuir pela metade os casos de malária, aumentar a vacinação infantil, impor tributos sobre poluição gerada na produção de energia, elevar a produtividade agrícola, e alcançar a educação primária universal na África subsaariana, entre outros. 


\section{CONCLUSÕES}

Como foi possível observar, institutos que deveriam ser meio de concretização da sustentabilidade, como a política energética ou os Objetivos do Desenvolvimento Sustentável, não alcançam seu pleno potencial nesse sentido por falta de estrutura informacional subjacente. Apesar do largo reconhecimento sobre os benefícios geracionais pela ampliação do uso de energia renovável, os gestores ainda não atuam suficientemente nesse sentido e tomam decisões que, caso houvesse informações mais amplas, seriam insustentáveis; e também apesar da publicação dos ODS, falta conhecimento sobre quais os mais relevantes e de cumprimento factível, obstaculizando sua efetivação.

Ou seja, a falta de ferramentas informacionais de subsídio ao processo racional de tomada de decisões, em um ambiente complexo como aquele promovido pelo reconhecimento da sustentabilidade, é um entrave para que a administração atue conforme seus objetivos constitucionais. Urge assim a adoção das técnicas contemporâneas de tomadas de decisão como verdadeiro dever funcional dos agentes públicos.

\section{REFERÊNCIAS}

ALCOFORADO, Fernando. A Política Energética Sustentável Requerida para o Brasil. Revista Nexos Econômicos, v. 6, n. 2, 2012.

BARAK, Aharon. Proportionality. Cambridge, 2012.

BREYER, Stephen; STEWART, Richard; SUNSTEIN, Cass R. Administrative Law and Regulatory Policy. 7. ed. Nova York: Wolters Kluwer, 2011.

COPENHAGEN CONSENSUS CENTER. Smart Development Goals. Disponível em http://www.copenhagenconsensus.com/sites/default/files/expert_outcome_one_pages_combin ed.pdf. Acessado em 12-03-2018.

DUTRA, Marques Ricardo; SZKLO, Alexandre Salem. A Energia Eólica no Brasil: Proinfa e o Novo Modelo do Setor Elétrico. Disponível em 
http://www.cresesb.cepel.br/publicacoes/download/artigo/CBE_XI-Artigo2.pdf. Acessado em 21-03-2018.

EUROPEAN COMISSION. Impact Assessment Guidelines. Disponível em http://ec.europa.eu/smart-regulation/impact/commission_guidelines/docs/iag_2009_en.pdf. Acessado em 13-03-2018.

FERGUSON, Niall. Populism as a Backlash Against Globalization - Historical Perspectives. Disponível em http://www.cirsd.org/en/horizons/horizons-autumn-2016-issueno-8/populism-as-a-backlash-against-globalization. Acessado em 23-03-2018.

FREITAS, Juarez. Políticas Públicas, Avaliação de Impactos e o Direito Fundamental à Boa Administração. Revista Sequência, n. 70, 2015.

FREITAS, Juarez. Sustentabilidade: direito ao futuro. 3. ed. Belo Horizonte: Fórum, 2016.

GATES, Bill. Dream with a Deadline: The Millennium Development Goals. 2013. Disponível em https://www.gatesnotes.com/Development/MDGs-Dream-with-a-Deadline. Acesso em 18-03-2018.

HONGBO, Wu. Discurso na 47 ${ }^{\mathrm{a}}$ Sessão da Comissão de Estatística das Nações Unidas. Disponível em https://unstats.un.org/unsd/statcom/47th-session/documents/2016-openingstatement-DESA.pdf. Acessado em 14-03-2018.

KONRAD ADENAUR FOUNDATION. Fact Sheet: The MDGs in Brazil. Disponível em http://www.kas.de/wf/doc/9942-1442-2-30.pdf. Acessado em 13-03-2018.

MALLOCH-BROWN, Mark. Entrevista concedida a Mark Tran. Disponível em http://www.theguardian.com/global-development/2012/nov/16/mark-malloch-brown-mdgsnuclear. Acessado em 12-03-2018.

NAÇÕES UNIDAS. Consensus Reached on New Sustainable Development Agenda to be adopted by World Leaders in September. 2015. Disponível em http://www.un.org/esa/ffd/ffd3/press-release/consensus-reached-on-new-sustainabledevelopment-agenda.html. Acessado em 14-03-2018.

NAÇÕES UNIDAS. The Millenium Development Goals Report 2015. Disponível em http://www.un.org/millenniumgoals/2015_MDG_Report/pdf/MDG\%202015\%20rev\%20(July \%201).pdf. Acessado em 10-03-2018.

NAÇÕES UNIDAS. World Investment report 2014 - Investing in the SDGs: an Action Plan. Disponível em http://unctad.org/en/PublicationsLibrary/wir2014_en.pdf. Acessado em 13-03-2018.

NAÇÕES UNIDAS. Report of the Inter-Agency and Expert Group on Sustainable Development Goals Indicators. Disponível em http://unstats.un.org/unsd/statcom/47thsession/documents/2016-2-SDGs-Rev1-E.pdf. Acessado em 12-03-2018. 
PIKETTY, Thomas. O Capital no Século XXI. São Paulo: Intrínseca, 2014.

SACHS, Jeffrey D. The Age of Sustainable Development. Nova York: Columbia University Press, 2015.

SACHS, Jeffrey D. Why the Sustainable Development Goals Matter. 2015. Disponível em https://www.project-syndicate.org/commentary/sustainable-development-goals-shift-byjeffrey-d-sachs-2015-03. Acessado em 11-03-2018.

SOUTH AFRICA. DEPARTMENT OF ENVIRONMENTAL AFFAIRS AND TOURISM. Cost Benefit Analysis. Disponível em https://www.environment.gov.za/sites/default/files/docs/series8_costbenefit_analysis.pdf. Acessado em 12-03-2018.

SUNSTEIN, Cass R. Cost-Benefit Analysis and the Environment. Revista Ethics, n. 115, 2005.

SUNSTEIN, Cass R. Simpler. Nova York: Simon \& Shuster, 2013.

SUNSTEIN, Cass R. The Cost-Benefit State: The Future of Regulatory Protection. American Bar Association, 2003.

SUSTAINABLE DEVELOPMENTS SOLUTIONS NETWORK. Indicators and a Monitoring Framework for the Sustainable Development Goals - Launching a Data Revolution for the SDGs. Disponível em http://unsdsn.org/wpcontent/uploads/2015/03/150320-SDSN-Indicator-Report.pdf. Acessado em 10-03-2018.

TENGS et al. Five Hundred Life-Saving Interventions and Their Cost-Effectiveness. Revista Risk Analysis, vol. 15, n. 3, 1995.

THALER, Richard H; SUNSTEIN, Cass R. Nudge - Improving Decisions About Health, Wealth and Happiness. Nova York: Penguim, 2008.

VENTURA FILHO, Altino. A Política Energética do Brasil. Revista Cadernos Adenauer, n. 3, 2015. 